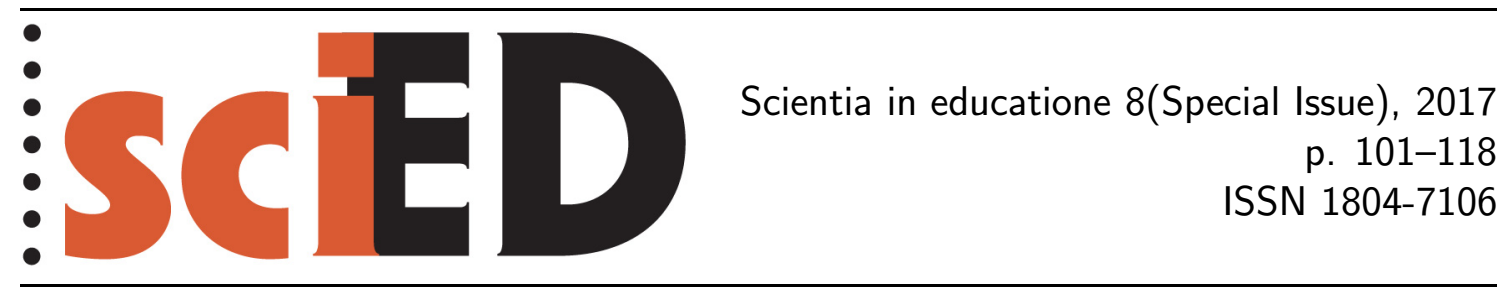

\title{
Active Learning and Teacher Training: Lesson Study and Professional Learning Communities
}

\author{
Kyoko Ishii
}

\begin{abstract}
Active learning is an innovation of teaching and learning and strongly connected to teacher education reform. A teacher's role in a knowledge-based society is being shifted from a knowledge teller to a facilitator. It is difficult to shift a teacher's perspective from "how to teach" to "how students learn." However, through a collaborative lesson study, teachers can discuss students' learning in a classroom. The university can function as a facilitator to cultivate a professional learning community.

This paper discusses the practice of active learning in teacher training at the University of Fukui in Japan. The faculty provides active learning for prospective teachers to engage collaboratively in scientific inquiry using physics by inquiry.

Based on the viewpoint that teacher development is a continuous, lifelong process, and the teacher is a reflective practitioner, teacher training should also be an active, lifelong endeavor. Moreover, the system and structure of the lesson study and collaborative reflection promote a professional learning community. Both pre-service and in-service teachers develop pedagogical content knowledge through repeated practice and reflection.
\end{abstract}

Key words: lesson study, community of practice, professional learning community, teacher training, intern, physics by inquiry. 


\section{INTRODUCTION}

Recently, the academics field has focused on the challenges of active learning; for example, the theme of the International Conference on Physics Education in 2013 was "Active learning - in a changing world of new technologies". The attention on active learning means that the interest of education has turned from "how to teach" to "how students learn". Therefore, active learning is an innovation of teaching and learning and strongly connected to teacher education reform.

Teacher training has concentrated on how to teach and has been conducted without students in places such as a university and a lecture hall. However, it is difficult to learn how students learn in such a situation. Education reform in active learning has not been promoted, and the study has not been collaboratively connected to school practice. Therefore, the importance of collaboration and the professional learning community is discussed (Lieberman \& Miller, 2008; Hargreaves, 1994), but is it clear how to cultivate and promote them?

The purpose of this paper is to clarify the strategy of active learning in teacher training. This paper therefore analyzes how the structure of active learning is brought into teacher education, particularly in Fukui Prefecture and the University of Fukui. ${ }^{1}$ The paper investigates the active teacher development process regarding the following practical theories:

1. The "teacher as a reflective practitioner" is well known from Schön's The Reflective Practitioner (1984).

2. Effective learning requires "active mental engagement", which is noted in Physics by Inquiry (McDermott \& Physics Education Group at the University of Washington, 1996).

The paper is organized as follows. First, it shows the purpose and background of this practice, such as the current situation of education and teacher education in Japan. Particularly, the lesson study as part of the culture of teacher training in Japan is introduced. Section 2 presents the new challenges of education in Fukui Prefecture and the University of Fukui. Section 3 demonstrates the three practices of active learning in teacher training in Fukui Prefecture and the University of Fukui. The first practice is the undergraduate course challenge using physics by inquiry (McDermott \& Physics Education Group, 1996) at the University of Fukui (Ishii \& Yamada, 2012). The second practice is the lesson study held in a lower secondary school in Fukui Prefecture. The third practice is the student teacher's lesson study and the curriculum of the graduate school at the University of Fukui (Ishii, 2011; Sasaki, 2011).

According to these three practices, this paper discusses how active learning is related to teacher training through cultivating the professional learning community.

\section{TEACHER AS A REFLECTIVE PRACTITIONER}

For many years, the primary objective of teachers has been to transmit a body of knowledge to their students. Teachers want to know how to teach effectively and want to master techniques for achieving this. Workshops have provided transmitted,

\footnotetext{
${ }^{1}$ Fukui Prefecture, with a population of 803200 and an area of $4189 \mathrm{~km}^{2}$, is located $320 \mathrm{~km}$ from Tokyo and borders Kyoto Prefecture. It has 330 schools and three education centers, including 30 professional development schools (PDS) with a strong relationship to the University of Fukui, which form the core of the distributed learning community.
} 
non-reflective experiences. However, it is time for this to change: teaching should be transformed into a process of lifelong professional development.

A teacher's development had previously been discussed as that of a professional practitioner (Schön, 1984). According to Schön, reflective teachers try to listen to their students; they ask themselves, "What do students think in a situation like this?" or "What is causing students' confusion?" It means teacher training must be changed.

The teacher's role should change from a knowledge teller to a facilitator supporting students' collaborative learning, a manager of a community, and a reflective practitioner. The focus must be changed from "how to teach" to "how students learn" because the purpose of education is to make students understand. Teacher training must prepare the opportunities to share teachers' experiences and steer the discourse toward students' learning.

\section{LESSON STUDY}

The lesson study is a traditional Japanese way of training teachers through actual "lessons" at the school. Lewis described it as "a process in which teachers jointly plan, observe, analyze, and refine actual classroom lessons" (2012). It was first introduced and covered extensively in the book The Teaching Gap (Stigler \& Hiebert, 1999). It has a long history in Japan and has become a central issue in educational practice and the professional development of teachers. There are many kinds of lesson studies, such as in-school, in the district, and at the national conference. Usually, a lesson study consists of a research lesson (open class) and debriefing, and it is conducted in a single day (National Association for the Study of Educational Methods, 2011).

Even though the lesson study originated in Japan nearly a century ago, it has spread its wings worldwide and is currently flourishing in several countries as a tool to promote the professional development of teachers. The lesson study is now growing in different ways, responding to a variety of social, cultural, and political contexts, and being applied to a range of disciplines. The World Association of Lesson Studies (WALS) was established in 2006 and has since held annual conferences to share the research and practice of the lesson study. More than 32 countries engage in lesson studies with the Japan International Cooperation Agency (JICA), AsiaPacific Economic Cooperation (APEC), and United Nations Educational, Scientific and Cultural Organization (UNESCO) (Akita, 2012).

Traditionally, the lesson study was considered a special opportunity for teachers to open their classes and show their lessons to their colleagues and supervisors. Before opening their classes, teachers were under pressure and feared how their lessons and teaching abilities would be rated. They prepared hard to make good lessons to show their colleagues or supervisors. Traditionally, a good teacher meant a technical expert. However, in the new trend, teachers are reflective practitioners, whose aim is to conduct case studies, enabling discussion of students' learning processes. As a result, in the new lesson studies, participants do not focus on teachers' activities but rather on children's learning (Sato, 2011).

\section{JAPANESE EDUCATIONAL SYSTEM — PAST AND PRESENT}

The educational system in Japan is centralized. Primary and lower secondary school (junior high school) is compulsory, and $98 \%$ of students go to high school for three years after compulsory education. Following high school graduation, $56 \%$ of stu- 
dents attend institutions of higher learning, such as university or college. A national curriculum (course of study) determines the contents of learning from primary school to high school for each grade. Textbooks authorized by the Ministry of Education, Culture, Sports, Science and Technology (MEXT) are distributed free to all students during the compulsory education phase.

Based on the course of study, science lessons focus on developing students' problem-solving skills, scientific thinking, and capacity for in-depth understanding (MEXT, 2008). Actually, many lessons have been teacher centered with an emphasis on transmitting knowledge (Murata \& Yamaguchi, 2010).

\section{EDUCATION REQUIRED IN A KNOWLEDGE-BASED SOCIETY}

The quality of Japanese education is shown in an international survey as Programme for International Student Assessment of Organisation for Economic Co-operation and Development (PISA-OECD) or Trends in International Mathematics and Science Study (TIMSS) (OECD, 2007). Japanese students have good scientific skills and demonstrate them well. Nonetheless, the survey reveals that they have difficulties applying their knowledge to novel situations and avoid solving unknown questions. Their science lessons have little connection to the real world. The rate of blanks on exams - in which students didn't write anything — is very high. Moreover, there appears to be a poor attitude toward studying. According to the OECD report on Japan, "Students who learn just to memorize and reproduce scientific knowledge and skills may find themselves ill-prepared for tomorrow's job market" (2007).

What does tomorrow's job market look like? What kind of innovation will be required in the future? In Japan, the industrial structure has changed in 50 years. The agricultural population is decreasing. The main professions have shifted from production of goods to designing, planning, generating ideas, publishing, marketing, advertising, distribution, and services. The workforce concentration is also changing from manufacturing products to services (Figure 1).

\section{population of engaged person is changing.}

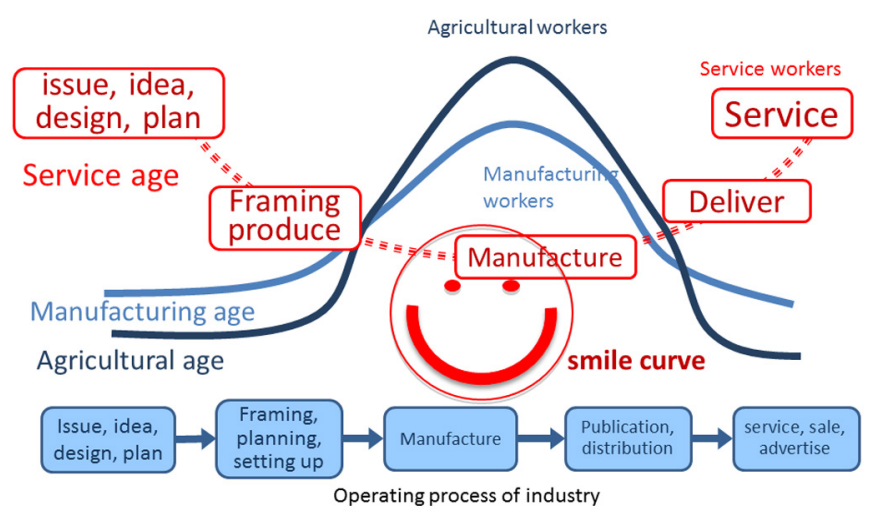

Figure 1: The industrial structure in Japan (smile curve)

In such a society, people require not only stored knowledge, but also the abilities of inquiry, collaboration, application of information, thinking, judgment, and expression, collectively called the smile curve. Therefore, students require active learning rather than listening and memorizing in school. 


\section{JAPANESE TEACHER EDUCATION SYSTEM}

Traditionally, a teacher's life is divided into three stages in Japan. The first stage is getting a teaching certification by going through a university course (4 years), teachers college (4 years), or junior college (almost 2 years) authorized by MEXT and by collecting credits. He/she reads books and discusses policy, history, and problems with education while gaining a certain number of credits. In general, a student needs to obtain a certain number of credits for specific teaching subjects and professional subjects. With some credits and only a four-week teaching practice in school, any student can obtain a teacher's license. The teacher's license is valid for all prefectures in Japan, but getting the certificate does not guarantee being hired as a teacher. Teachers are recruited by each prefecture, in other words, by the government. For example, 178461 students earned a teacher's license in 2009, but less than $10 \%$ or only 17272 students were employed as teachers (Figure 2, left).

The second stage is employment. Prospective teachers must take an examination to be hired by the local board of education. After they pass the examination and are employed, they start their teaching career. The third stage is on-the-job training in school, with little relationship with universities, meaning that the responsibility for teachers' development is handled by schools. In the traditional Japanese teacher education system, the pre-service and in-service training phases are separated. The university seems to be separated from the local board and schools (Figure 2, right).

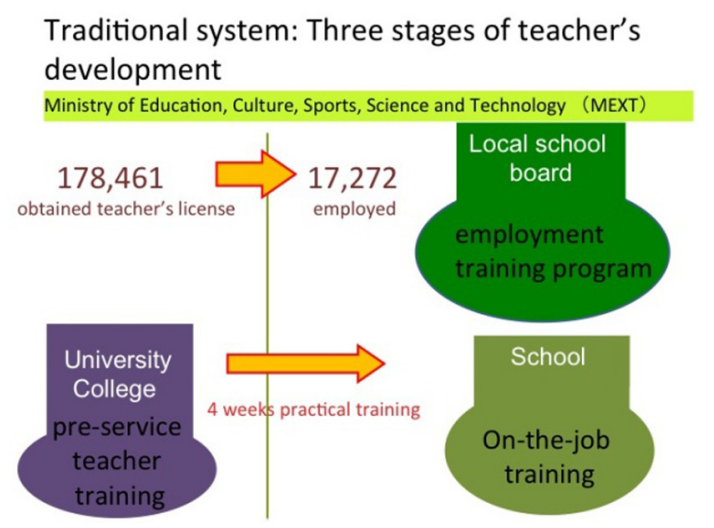

Fukui system: School-based graduate school

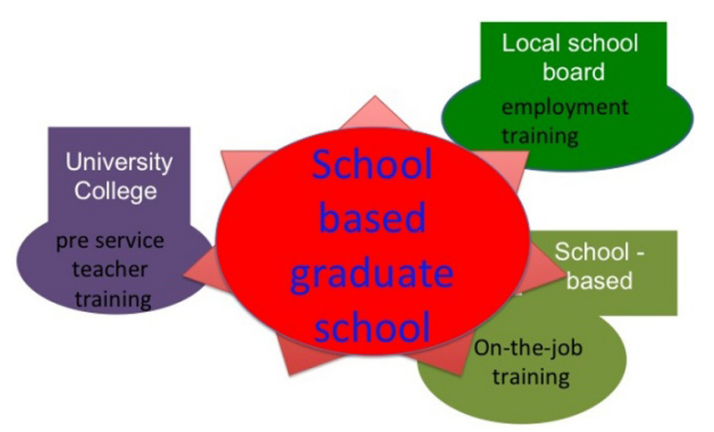

Figure 2: The three stages of the traditional teacher's development (left) and Fukui system (right)

\section{System and curriculum of the Graduate School of EDUCATION, UNIVERSITY OF FUKUI}

The Graduate School of Education's Department of Professional Development of Teachers at the University of Fukui (DPDT-Fukui) was established in 2008. The system called "school-based, collaborative practice research" represents an innovation in the teacher training system (University of Fukui, 2002). In other words, the graduate school is taking place in schools. Instead of attending a university to learn teaching and learning by reading and hearing, in-service teachers train in school and invite university faculty members to discuss about the actual classroom situation. Pre-service teachers stay in the same school to learn teaching and learning together. In each school, lesson studies, action research, and collaborative learning are held. This arrangement is called a school-based graduate school system with a professional development school (PDS), which constitutes a major challenge in the innovation of teacher training in Japan (Figure 3). 


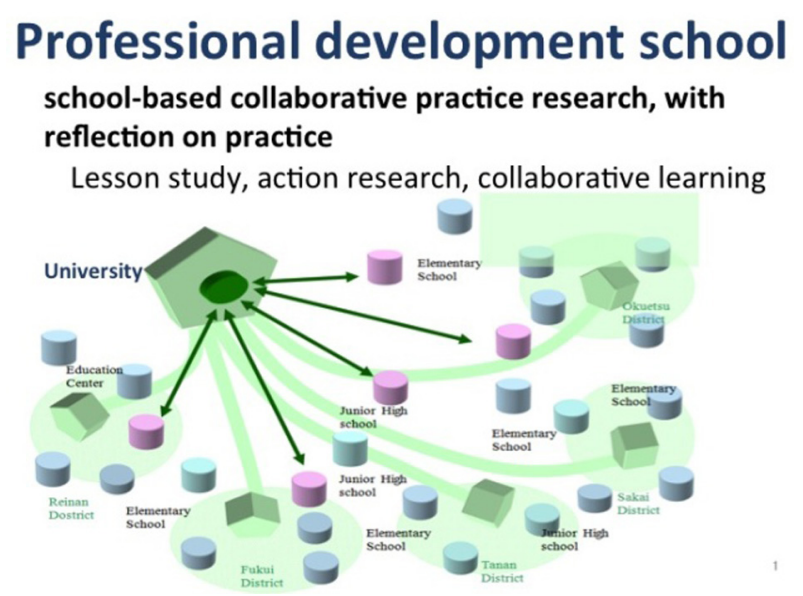

Figure 3: School-based graduate school system (University of Fukui)

The curriculum of this graduate school is based on the viewpoint embodied in the concept of community of practice (Wenger et al., 2002). Both pre-service and in-service graduate students reflect on their own practices from the community of practice perspective. The main curriculum, known as "longitudinal, collaborative action research based in schools", consists of reflections on practice. Lessons are developed around discussions about teachers' own practices, listening to one another, reading case studies and theories, and writing about the processes involved in their own teaching practices. They share their practices, observe one another's practices, and reflect together. The research of the teachers and university faculty is based on practice.

\section{INTERN SYSTEM FOR PRE-SERVICE TEACHER TRAINING}

Another major challenge involves the intern system for pre-service teacher training, which also takes place mainly in schools. Graduate students spend three days a week in school as interns (student teachers) and attend university two days a week for a year. This system also entails school-based, collaborative practice research; the main curriculum is the same as that of the in-service type, "longitudinal, collaborative action research based in schools". Each intern has a mentor who is an in-service graduate student in the same school. They open their classes with each other and attend the lesson study together. The professor goes to their school to participate in the lesson study. The new graduate school system tries to connect the three stages of the teacher's development.

\section{Practice 1: ACtive LeARning in Undergraduate COURSES USING PHYSICS BY INQUIRY}

This section discusses the challenges of the undergraduate course using physics by inquiry (McDermott \& Physics Education Group, 1996). From the viewpoint of teacher development as a lifelong process, learning physics actively to prepare teachers is needed. Developed by the University of Washington, physics by inquiry is designed as a set of laboratory-based modules to help teachers develop a functional understanding. 
Undergraduate courses for pre-service teachers should be seen as the starting point of their lifelong teaching careers. However, undergraduate students have a strong belief that studying is just memorizing and reproducing knowledge, based on their prior experiences before entering university. Therefore, they should have an opportunity to engage in scientific inquiry. They cannot teach active learning without themselves experiencing how to learn actively.

We have developed a teacher training program aimed at deepening the scientific understanding of teachers-in-training and have investigated the effects of using physics by inquiry (Ishii \& Yamada, 2012).

\section{COMPARISON BETWEEN JAPANESE NATIONAL CURRICULUM AND PHYSICS BY INQUIRY}

In the national curriculum (course of study), single-bulb circuits are introduced in the third grade; parallel and series circuits in the fourth grade; and voltage, resistance, and Ohm's law in the second grade in junior high school (eighth grade) (MEXT, 2008). In the third grade, students investigate how to light a bulb in a circuit. They engage in experiments, discuss them, and write down their conclusions. Conclusions such as "When a battery $(+)$, bulb, and battery $(-)$ are connected in a circle, electricity goes through and the bulb lights up" are written in the textbook.

On the other hand, physics by inquiry is designed to develop basic physical concepts and reasoning skills; construct explanatory models with predictive capability; and gain practice in relating scientific concepts, representations, and models to real-world phenomena (McDermot \& Physics Education Group, 1996).

The developed program covers direct-current electrical circuits, a topic studied in the third and fourth grades of primary school.

\section{PraCtice AND INVESTIGATION}

The developed program was implemented during the 2012 spring term for 15 weeks from April to July. The participants comprised 100 students at the Faculty of Education and Regional Studies of the University of Fukui (65 women and 35 men, aged 19-25). Most of the participants were in the first year of a four-year teacher education program for primary school. Some had studied physics before, and others had not.

The students' conceptual understanding was analyzed with pre-/post-tests by using DIRECT version 1.2 (Engelhardt \& Beichner, 2004). The participants took identical tests before the practice and 1-4 weeks afterward. Although the students learned about electrical circuits, they forgot the meaning of circuit. In other words, they had difficulties in understanding what a circuit is.

The results of the pre-test and interview found that students have typical misconceptions such as "the battery delivers a constant current" and "the current is used up". This is actually reasonable because we often say "This battery is finished".

The participants were divided into 25 groups, consisting of four students each. They were fully engaged in the program and learned actively, even though it lasted 180 minutes. They enthusiastically discussed the topic and conducted experiments. From the pre- to post-test analysis, the mean score increased from $38.9 \%$ to $46.4 \%$.

The discourse analysis revealed that most groups faced cognitive conflicts during the experiments and discussions about series and parallel circuits. 


\section{DiSCOURSE ANALYSIS}

In the lesson about physics by inquiry, the students used their own concepts to hypothesize about and reason through the phenomena. At the experiments, they faced cognitive conflicts as they were unable to explain any further using their concepts. They discussed and did the experiments again and again. Finally, they changed their concepts and explained the phenomena by themselves. This means they constructed the concept socially.

A brief example of four students' discussion in a parallel circuit experiment concerns the question:

"Compare the brightness of each of the bulbs with the brightness of an identical bulb in a single-bulb circuit" (McDermot \& Physics Education Group, 1996: p. 395).

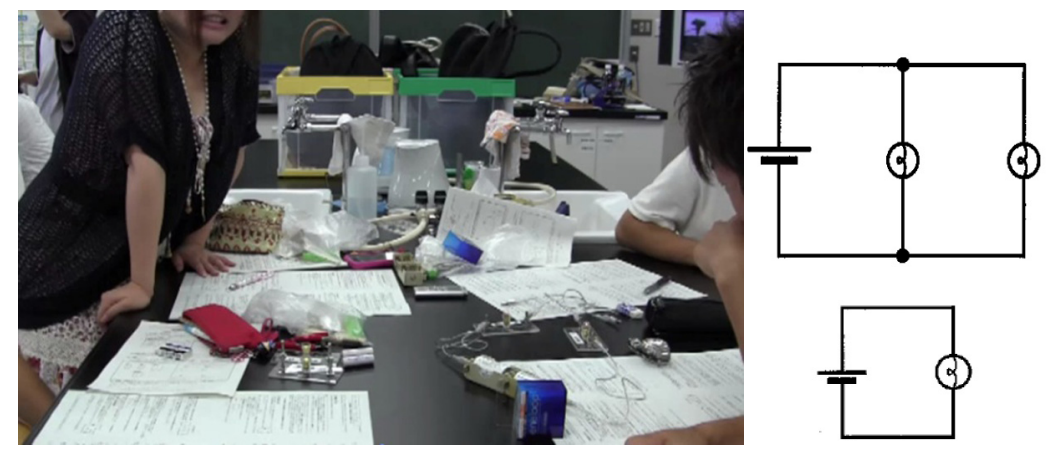

Figure 4: The students discussing about the current in a parallel circuit

Figure 5. Shows a typical discussion dialogue illustrating cognitive conflicts between a previous concept and a real phenomenon. Figure 4 shows the discussion and equipment on the table.

Student A: I don't know why. I wonder why the bulbs don't get dimmer when they're connected in parallel.

Student B: But the current at the battery should be the same as a single circuit.

Student C: The two bulbs lit up but the current is the same. Is this OK?

Student A: I think the current should be twice as much, to compare with a single circuit.

Figure 5: Dialogue about the current in a parallel circuit

Student B presented the strong belief that a battery provides the same current anytime. However, Student A asked the group why it is not consistent with the phenomenon. After the discussion, they started to investigate the brightness of a single circuit again.

\section{FINDINGS FROM PRACTICE IN UNDERGRADUATE COURSES}

Physics by inquiry is engaging and provides the opportunity to learn physics in depth. It is effective for Japanese university students. It provides ideal experiences of reasoning and facing cognitive conflicts. Pre-/post-test results indicated that conceptual difficulties were considerable and widely encountered. The discourse analysis suggested that expressing a concept elicited their own thoughts, exchange of ideas, and reconstruction of the concept. Step-by-step exercises led the students 
to a conceptual understanding. Moreover, teaching assistants were able to serve as facilitators rather than knowledge tellers. From the discourse analysis, many students formulated a concept of the conservation of electrical current in a circuit.

To encourage active discussion and better understanding, relations within the group and an atmosphere allowing free expression without stress are important. Especially when someone says "I don't know", the discussion becomes active. To promote inquiry, facilitation such as "teaching by asking" is effective.

\section{Practice 2: Lesson STUdy in A SCHOOL With A LOCAL TEACHERS' COMMUNITY}

This section provides an example of a lesson study, which occurred on October 17, 2012 in Fukui Prefecture. Nearly 30 teachers gathered from all areas of Fukui Prefecture and other prefectures. The members of the school board, university professors, pre-service graduate students, and undergraduate students also participated in the lesson study. As usual, the lesson study consisted of a research lesson and debriefing, and it was conducted on the same day.

\section{THE RESEARCH LESSON}

The topic was "How is light reflected?" The objective was to explore and understand how light is reflected. The target comprised first graders in junior high school (12 and 13 years old). There were 14 boys and 14 girls divided into 7 groups of 2 boys and 2 girls each. This lesson lasted for 70 minutes.

The lesson had four phases.

Phase 1. Observe the "ball" reflection.

Phase 2. Conduct a group discussion.

Phase 3. Share ideas in class.

Phase 4. Apply the rule to "light" reflection.

Figure 6 shows Phase 1. The teacher assigned the day's task to the class: "Let's play billiards. Shoot a ball into a pocket."

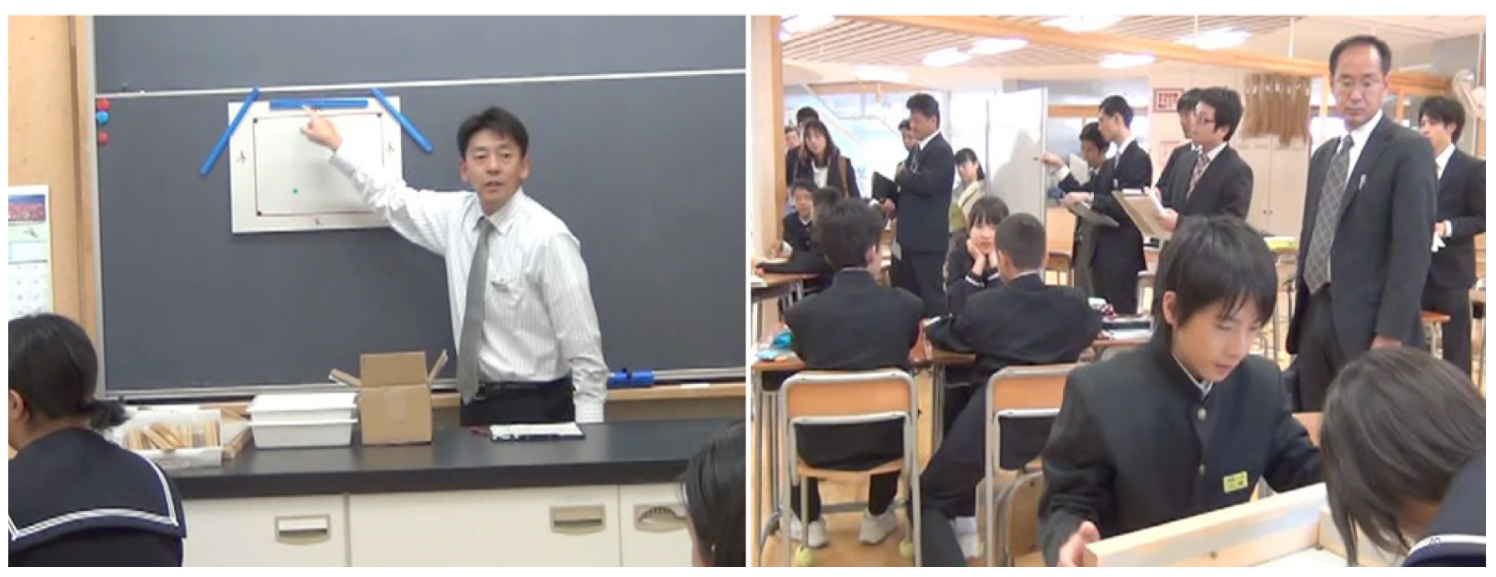

Figure 6: Phase 1: Observe the "ball" reflection

The word "billiards" sounded interesting for the students. Many students became curious about billiards and wanted to play the game. Each group had an experiment table and a whiteboard. They started to examine how a ball is reflected. They observed the ball and tried to find the role of reflection. 

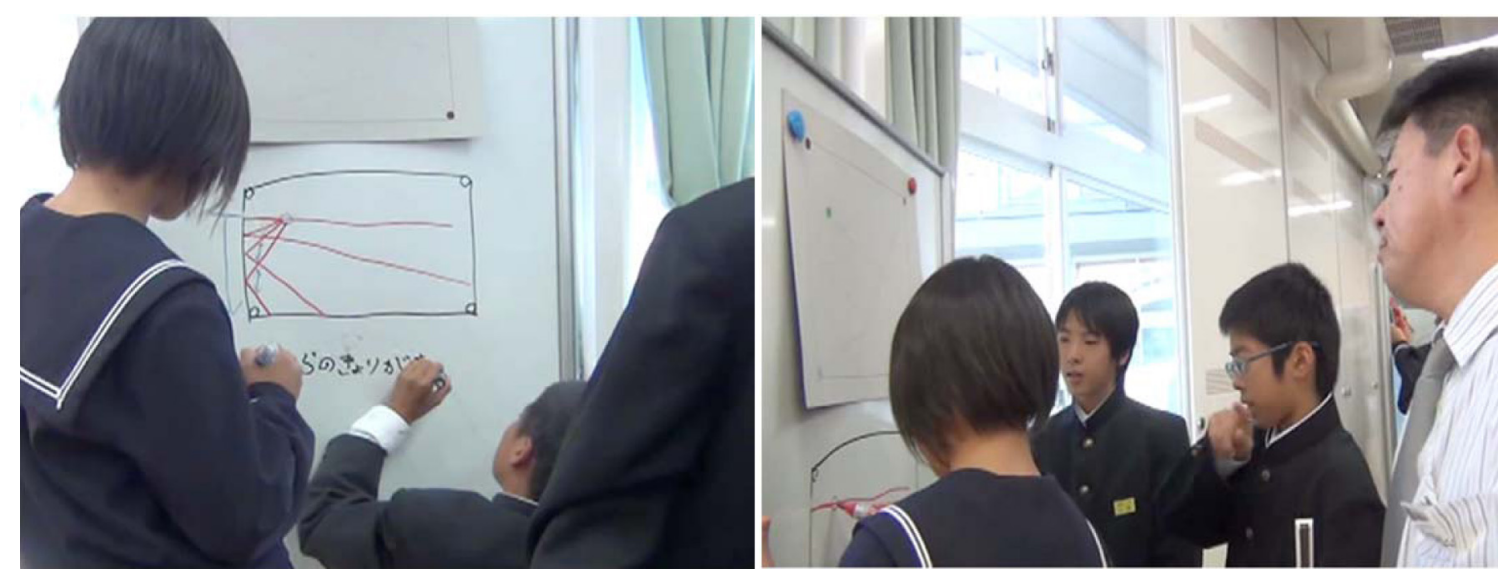

Figure 7: Phase 2: Group discussion and the teacher

Figure 7 illustrates the group discussion in Phase 2.

Each student expressed and discussed his or her thoughts regarding the words, pictures, and diagrams on the whiteboard to discover the role of reflection. The teacher visited each group to listen to the students' discussion and to ask occasional questions. The participants observed and listened closely to one or two group discussions.

The students discussed how to present their findings in front of the whiteboard.

Figure 8 shows the students sharing ideas in the class (Phase 3).

Some of the groups explained their findings to the whole class using their whiteboards. They shared that all of them found the same principle, that a ball reflects the same angle. Finally, the teacher explained the name of the incident angle.

The teacher asked the students to apply the rule of ball reflection to light reflection (Phase 4, see Figure 9). "Let's play another game. How do we light the doll in the center with a flashlight and eight mirrors?"

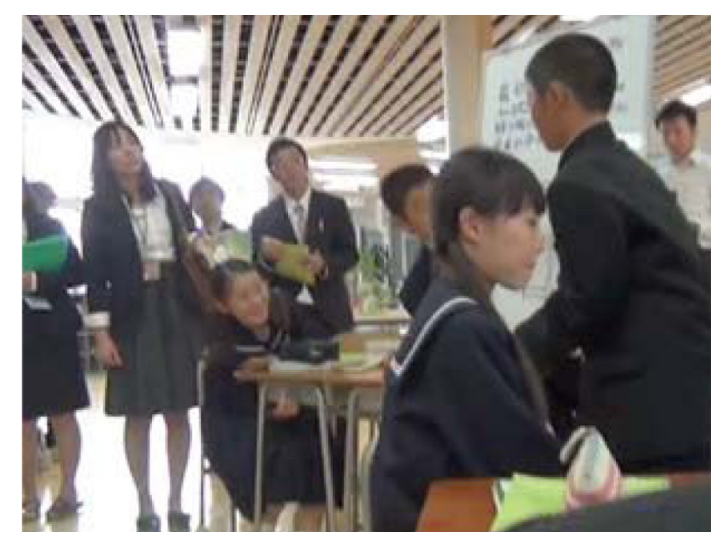

Figure 8: Phase 3: Share ideas in the class

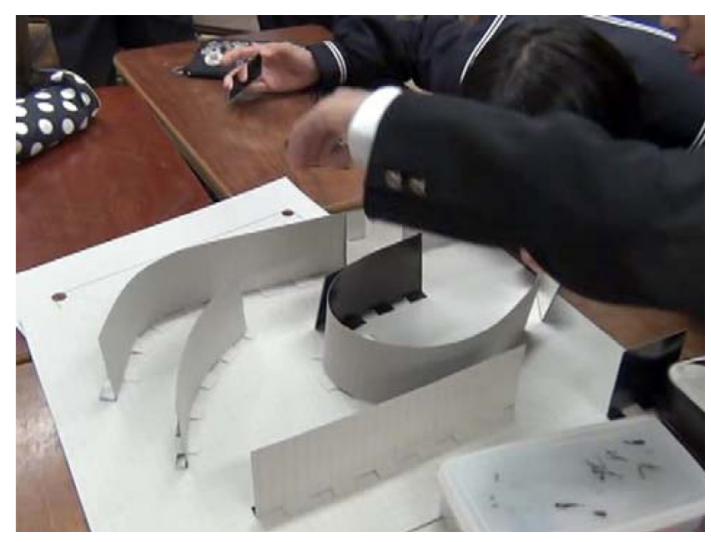

Figure 9: Phase 4: Apply the rule to light reflection

\section{DEBRIEFING AFTER LESSON (COLLABORATIVE REFLECTION)}

After the lesson was finished, the participants discussed the students' learning process in small groups. They sat at the same tables from which they observed the students and shared their findings (Figure 10). 


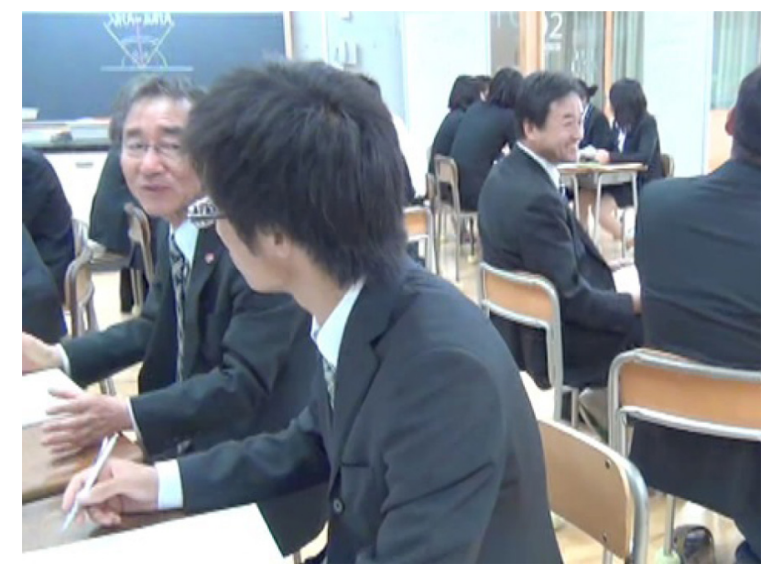

Figure 10: Debriefing (group discussion)

The participants held discussions based on their observations of the students' performance. An example is shown in Figure 11.

\begin{tabular}{|c|c|}
\hline Teacher A: & $\begin{array}{l}\text { "At first, they didn't realize the rule of reflection. But when this } \\
\text { boy succeeded in getting a ball into the pocket, the girl found the } \\
\text { path of the ball. After that, they started to discuss actively." }\end{array}$ \\
\hline Teacher B: & $\begin{array}{l}\text { "I saw the girl so precisely. She looked very curious. When they } \\
\text { started to talk in front of the whiteboard, she took the pen } \\
\text { immediately and started to draw a diagram. But they didn't have } \\
\text { the idea of the difference of [the] angle." }\end{array}$ \\
\hline Teacher C: & $\begin{array}{l}\text { "The students didn't express the incident angle on the whiteboard. } \\
\text { But they discussed the length of the pathway. I think they noticed } \\
\text { that the angle is two times the incident angle. We can consider this } \\
\text { to be finding the rule of reflection." }\end{array}$ \\
\hline
\end{tabular}

Figure 11: Dialogue excerpt from a group discussion

After the small-group discussions, one teacher represented each group to share what was discussed in their respective groups (Figure 12).

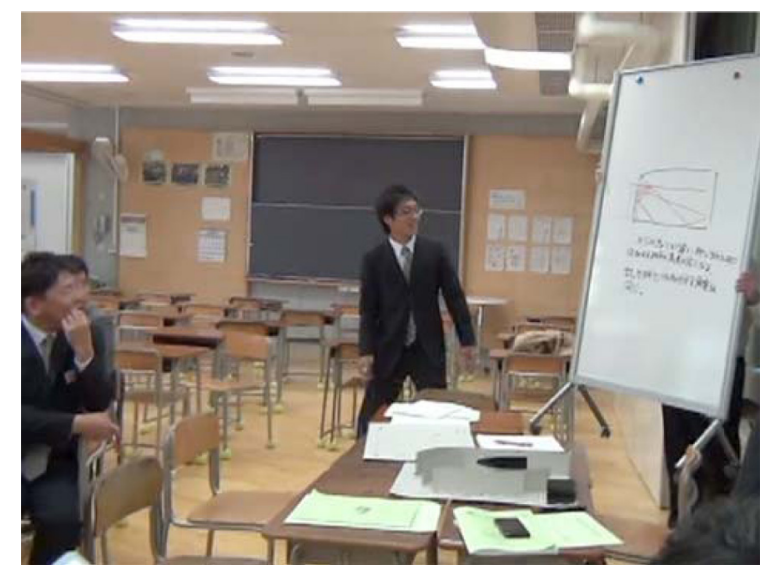

Figure 12: Debriefing (sharing of group discussions) 


\section{FINDINGS FROM THE LESSON STUDY PRACTICE IN THE LOCAL}

\section{TEACHERS' COMMUNITY}

At each table, each participant discussed the performance of the students. The teachers must observe the students' learning and present their findings. Presented with the actual lesson, everybody learns how students learn.

Professional development, which is asked for by in-service teachers, must be supported by practical and collaborative research from organizations that face actual problems and are appropriate for professionals. The cooperation and collaboration of universities, education boards, and schools should form a framework for new teacher education. Through these practices, the university and local professional networks can support the learning community in schools and the distributed community of local teachers.

The new trend in the lesson study focuses on the learning process of students, not the teacher performance. The experience of discussing the learning process of students with colleagues is supported and facilitated by the university. If colleagues construct a learning community, teachers will be stress-free and try to promote students' learning.

\section{Practice 3: Practice and Reflection of an INTERN - YOSUKE'S STORY}

This section presents an example of one intern's lesson study (Sasaki, 2011). Yosuke Sasaki, aged 23, was a graduate student at the University of Fukui. He was an intern at Shimin Junior High School, the same school where practice 2 was held. Yosuke's practice was about sound for the first grade of junior high school, which occurred in September 2010.

\section{YOSUKE's STORY — SOUND}

Before the lesson, Yosuke came to the university to discuss and make a lesson plan covering the topic of sound. He decided that the first lesson would be about loudness, and the second lesson would be about high and low frequencies, because these topics seemed easy (Figure 13).

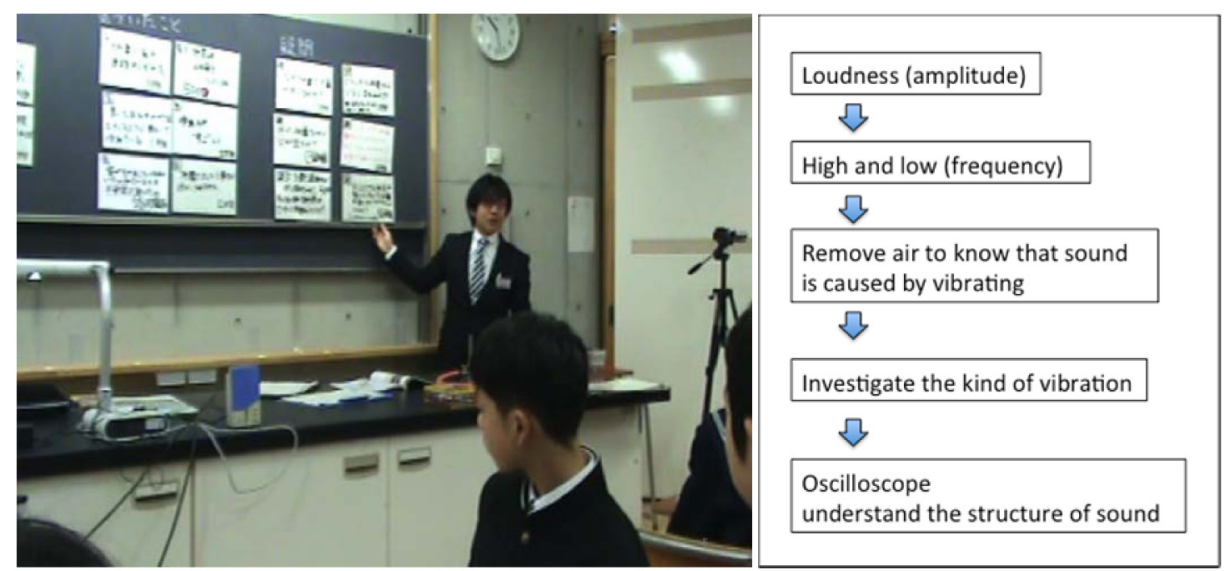

Figure 13: First lesson and first lesson plan of Yosuke (an intern) 
At the first lesson, Yosuke taught about loudness and prepared the second lesson as planned. At the second lesson, Yosuke asked the students to make various sounds with a wine glass and mono cord and to think about what the sounds were like. He told them: "Loudness is amplitude, as you learned yesterday. Let's explore high sound and low sound today." At that time, he believed that the students understood that loudness is amplitude because he had "taught" it to them in a prior lesson (Figure 14).

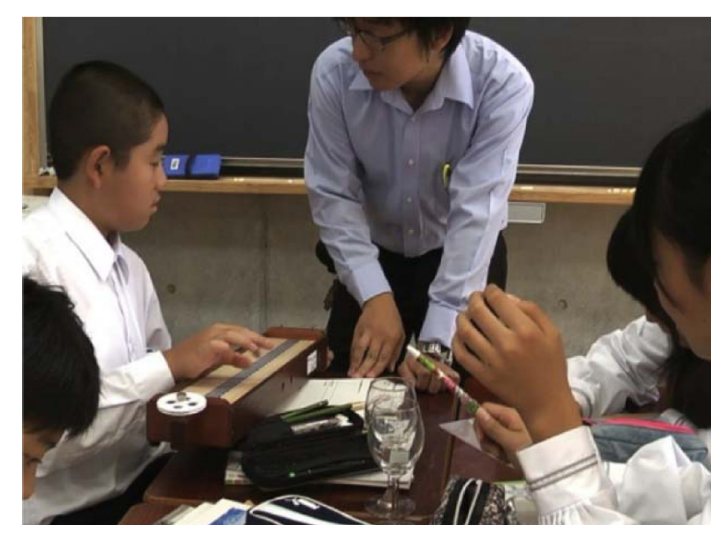

Figure 14: Second lesson about high and low frequencies

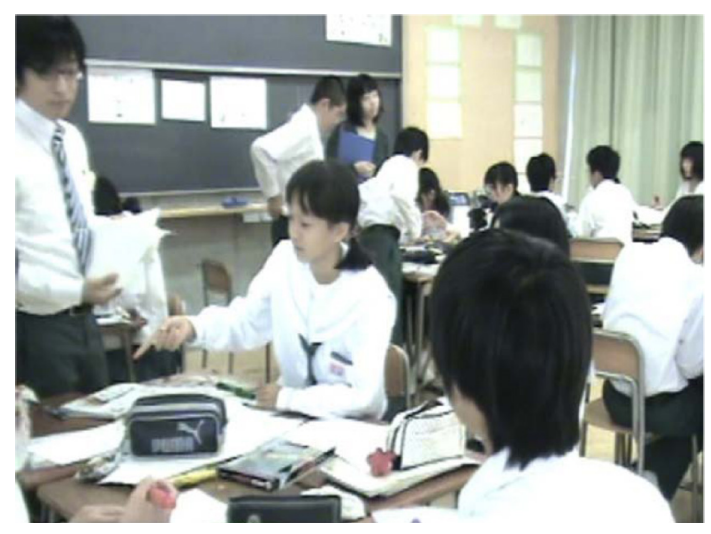

Figure 15: Yosuke's confusion about why the students were playing

The students started to make various sounds and investigate them. However, some students made loud, high, small, and low sounds randomly. They just looked like they were playing with instruments. They did whatever they wanted and did not seem motivated (Figure 15).

Yosuke was confused and asked himself: "Why aren't they examining high and low? Why are they making various messy sounds? Why don't they follow my assignment?" He went to each group to facilitate their investigation. At this point, he wanted students to conduct the "right" type of investigation.

Many colleagues observed this lesson. Another intern listened to the students talking; a mentor (in-service graduate student) observed what they were trying to do.

After the lesson, Yosuke reflected on his lesson with the professor, other interns, and his mentor (Figure 16).

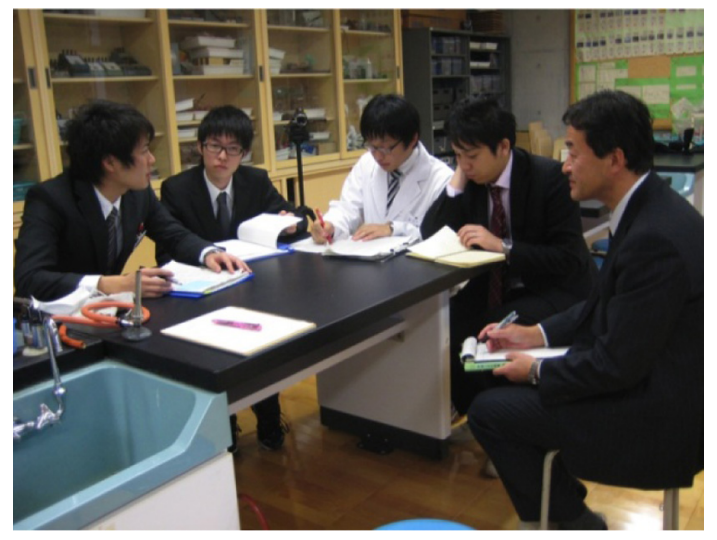

Figure 16: Debriefing with other interns, mentor, and professor

After the lesson, Yosuke and the observers collaboratively reflected on the lesson. They exchanged their observations about each student's actions and words, as well as discussed how and what they learned. The mentor told him, "The pupils analyzed 
sound their own way, although they looked like they were playing." Another intern said, "The boy I observed seems to be confused about what to do. Does the pupil recognize the difference between frequency and loudness?"

Yosuke realized that the students wanted to investigate by themselves. They were not unmotivated; they merely followed their own interests, not the teacher's. He realized that he just pushed the inquiry process to the students. He tried to reconsider and redesign the lesson plan.

At the last lesson on sound, Yosuke tried to connect content knowledge with the students' interest. He arranged the oscilloscope to analyze a pupil's voice easily. He asked the students, "What does the oscilloscope show?" They then investigated more eagerly and found the wavelengths of high and low sounds (Figure 17).

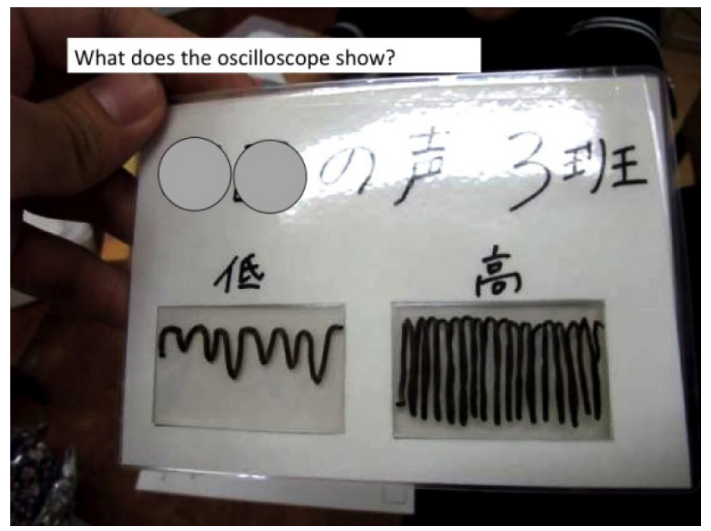

Figure 17: Last lesson: investigation on what the oscilloscope shows

After all the lessons were finished, Yosuke reflected again on his own practice. He realized his insistence on his first lesson plan; however, to facilitate diverse students' learning, he should apply more flexibility in creating the lesson plan. Then he reconstructed the content of the lesson by portraying sound as a dynamic structure (Figure 18).

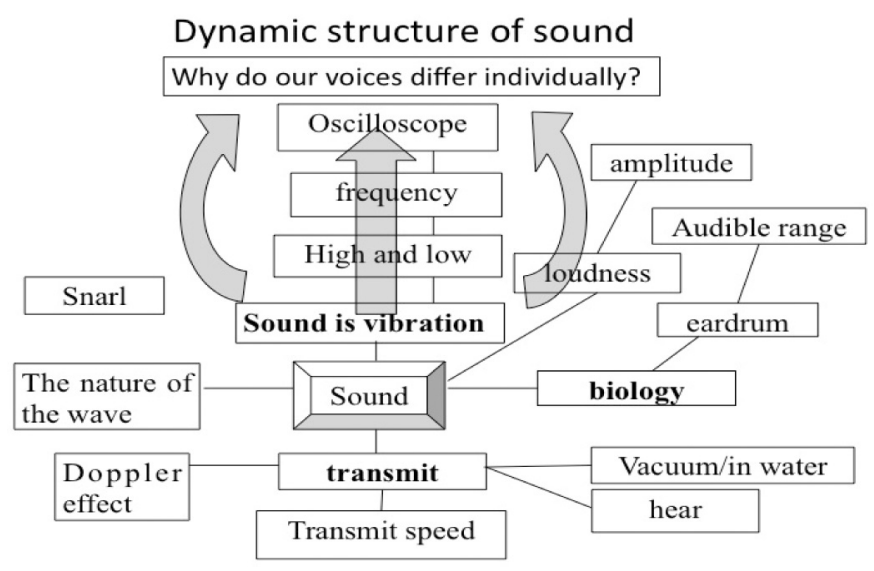

Figure 18: Dynamic structure of sound after Yosuke's reflection

Through this process, he was able to address any student reaction - and the reactions were quite varied. This reconstruction of the lesson content is an important pedagogical phase. Lesson plans do not fit all classes, especially when they involve incorporating active learning into a lesson. It is difficult to teach this fact to novice teachers or students unless they practice it themselves. 
Creating such a dynamic structure to design a lesson is considered one of the teacher's skills, called "pedagogical content knowledge (PCK)" (Shulman, 1987). It is said that teachers need a lot of experience and time to acquire PCK.

\section{STRUCTURE AND LEARNING COMMUNITY TO SUPPORT INTERNS' DEVELOPMENT}

How did Yosuke acquire PCK in such a short time? The structure of the curriculum and the learning community support the interns' development. As shown in Yosuke's year cycle, interns repeat practice and reflect on the lessons many times (Figure 19).

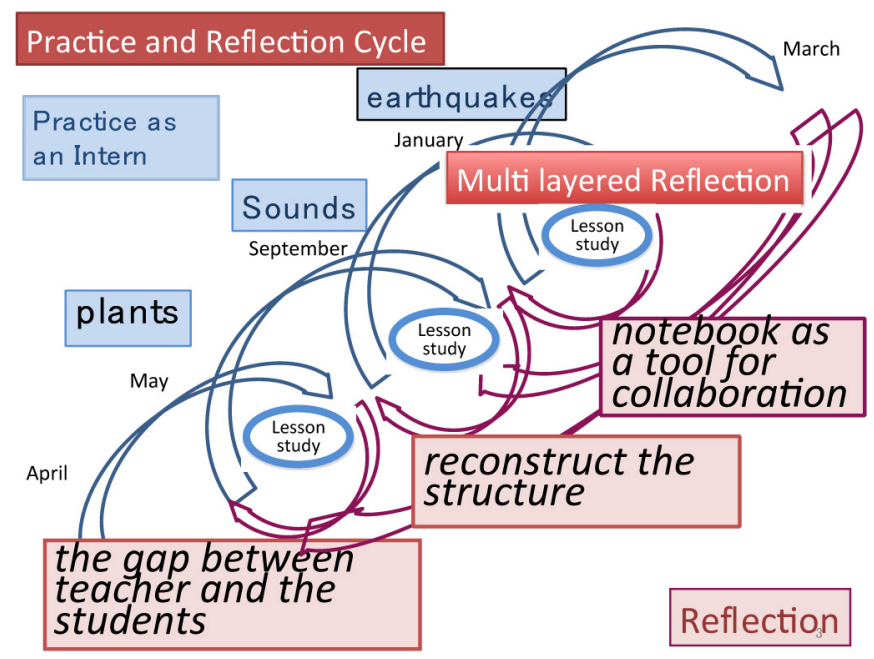

Figure 19: Year cycle of practice and reflection of an intern

The lesson study provides interns with many opportunities for practice and reflection in the course of one year. Yosuke repeated three practice sessions in one year: plants in May, sounds in September, and earthquakes in January. During each practice, many colleagues, professors, and the mentor observed his lesson and reflected on it together. At the first lesson, Yosuke encountered a gap between the teacher and the students. Through his reflection on his second practice on sound, he realized the importance of reconstructing the topic before designing a lesson plan. In his third practice on earthquakes, he used the whiteboard and students' notebooks as tools for communication and facilitation of the students' inquiry.

Yosuke wrote about his practice:

The main and important thing in my learning process is reflection and community. My community is various, as intern colleague, PDS, graduate school, and science seminar, etc. I talked with different people, and think again, write my practice and thought. My thought became clear and tacit knowledge comes up to be shown. (Sasaki, 2011).

The yearlong cycle of an intern is designed to enable him/her to do practice and reflection repeatedly. The curriculum of interns is designed to enable them to observe lessons, teach, perform special activities, etc., in school. Once a week they gather at the university to share their reflections together with professors. They read books and discuss and write their theses with in-service graduate student teachers and university faculty during weekends and the summer and winter holidays. Such repeated reflections with different colleagues have been named "multilayered reflections". 


\section{FINDINGS FROM PRACTICE OF LESSON STUDY IN THE LOCAL TEACHERS' COMMUNITY}

The reflection and practice cycle creates opportunities to develop the pre-service students' reflective thinking skills and support their potentials as professionals. The interns' thoughts become integrated and based on multiple perspectives. Student teachers establish their beliefs and theories through integrating experiences and knowledge.

At the lesson study, not only interns but also mentors and professors learn a lot from students learning in the classroom. Therefore, the intern system presents one of the challenges to cultivate a learning community.

\section{Conclusion}

This report has discussed active learning in teacher training with three practices at Fukui Prefecture and the University of Fukui. The results show that to cultivate a learning community, each participant should learn actively from the lesson study and communicate dynamically. The students learn actively from the phenomenon with group discussions in the first practice. At the graduate school, all participants both students and teachers - learn active, collaborative, and reflective strategies in the practice.

The National Science Education Standard notes the standards for professional development:

Although learning science might take in a science laboratory, learning to teach science needs to take place through interactions with practitioners in places where students are learning science, such as in classrooms and schools.

Provide regular, frequent opportunities for individual and collegial examination and reflection on classroom and institutional practice (National Committee on Science Education Standards and Assessment, 1996).

In the lesson study, observing and discussing the students' learning in a collaborative manner constitute active learning for the teachers. To cultivate and promote a professional learning community, it is vital to provide opportunities for collaborative reflection in the classroom, such as through the lesson study and repeated cycle of practice and reflection. The curriculum of the University of Fukui is designed with active, collaborative, and reflective engagement in the professional learning community.

In conclusion, it is clear that collaborative and continuous learning based on "reflective practice" is the essence of teacher training. To enhance awareness of how students learn, collaborative reflection on the lesson by the professional learning community is effective. If colleagues build a learning community, teachers will have their stress levels reduced and will try to promote students' learning. The university can function as a facilitator to cultivate a professional learning community. Both pre-service and in-service teachers develop pedagogical content knowledge through repeated practice and reflection. 


\section{ACKNOWLEDGEMENT}

The author gratefully acknowledges all the teachers and students who were involved in the lesson study and collaborative research. She also thanks Dr. Yoshihide Yamada and Mr. Yosuke Sasaki for participating in this program; without their cooperation, this project would not have been possible.

\section{REFERENCES}

Akita, K. (2012). Building learning and caring communities through high-quality lesson studies. [online]. Available from http://www.walsnet.org/2012/keynote-speakers.html

Engelhardt, P. \& Beichner, R. (2004). Students' understanding of direct current resistive electrical circuits. American Journal of Physics, 72(1), 98-115.

Hargreaves, A. (1994). Changing teachers, changing times: Teachers' work and culture in the postmodern age. Teachers College Press.

Ishii, K. (2011). The professional development of a science teacher as a reflective practitioner. Studies in and on Teacher Education, 4, 243-254 (in Japanese).

Ishii, K. \& Yamada, Y. (2012). Teacher training program using active learning based on physics by inquiry. WCPE 2012 Proceedings.

Lewis, C. (2012). What is lesson study? Lesson study group at Mills College. Available at http://www.lessonresearch.net/index.html

Lieberman, A. \& Miller, L. (2008). Teachers in professional communities. Teachers College Press.

McDermott, L. (1996). Physics Education Group at the University of Washington. Physics by inquiry Volumes I and II. New York: John Wiley \& Sons, Inc.

Ministry of Education, Culture, Sports, Science \& Technology in Japan. (2008).

Improvement of academic abilities (Courses of study). Available at

http://www.mext.go.jp/english/elsec/1303755.htm

Murata, Y. \& Yamaguchi, M. (2010). A bilingual text: Education in contemporary Japan - System and culture. Toshindo.

National Association for the Study of Educational Methods. (2011). Lesson Study. Keisuisha.

National Committee on Science Education Standards and Assessment. (1996). National Science Education Standard.

Organisation for Economic Co-operation and Development. (2007). Programme for International Student Assessment (PISA) 2006 science competencies for tomorrow's world. Available at http://www.oecdtokyo2.org/pdf/theme_pdf/education/20071204sg_speech.pdf

Sasaki, Y. (2011). The process of constructing a lesson with collaboration and reflection. (in Japanese).

Schön, D. A. (1984). The reflective practitioner: How professionals think in action. New York: Basic Books.

Shulman, L.S. (1987). Knowledge and teaching: Foundations of new reform. Harvard Educational Review, 57, 1-22. 
Stigler, J. \& Hiebert, J. (1999). The teaching gap: Free press reprint.

University of Fukui, Faculty of Education and Regional Studies. (2002). Design of Japanese teacher education reconstruction in 21st century. Center for Network and Collaboration Supporting Regional Education Reconstruction.

Wenger, E. et al. (2002). Communities of practice: A guide to managing knowledge. Harvard Business School Press.

KYOKO ISHII

Faculty of Education, Tamagawa University, Tokyo, Japan

Department of Professional Development of Teachers,

Graduate School of Education, University of Fukui, Fukui, Japan 